\title{
KONTRIBUSI LATIHAN HAND GRIP DAN LATIHAN BACK-UP TERHADAP SERVIS SLICE PADA ATLET PUTRA KOMUNITAS TENIS LAPANGAN UNIMED
}

\author{
Debora Tarihoran, Mahmuddin, Nono Hardinoto \\ Fakultas Ilmu Keolahragaan, Universitas Negeri Medan \\ Deboratarihoran0@gmail.com,Mahmuddin.matondang1977@gmail.com, hardinoto@unimed.ac.id
}

\begin{abstract}
Abstrak: Penelitian ini bertujuan untuk mengetahui kontribusi latihan hand grip dan back up terhadap servis slice dalam permainan tenis. Adapun sampel penelitian ini berjumlah 6 orang atlet putra diperoleh dengan teknik purposive sampling. Instrumen yang digunakan dalam penelitian ini adalah grip strength dynamometer untuk kekuatan genggaman, trunk and neck flexibility test untuk kelentukan, serve test untuk servis slice. Hasil analisis statistik latihan hand grip terhadap servis slice diperoleh $\mathrm{F}_{\text {hitung }} 0.151$ dan $F_{\text {tabel }(4,5)}$ sebesar 5.19. Karena $F_{\text {hitung }}<F_{\text {tabel }}(0.151<5.9)$. Sedangkan nilai Sig $>\alpha(0.717>0.05)$ maka dapat disimpulkan bahwa tidak terdapat kontribusi yang signifikan dari latihan hand grip terhadap servis slice. Hasil analisis statistik latihan back-up terhadap servis slice diperoleh $\mathrm{F}_{\text {hitung }} 0.176$ dan $\mathrm{F}_{\text {tabel }}(4,5)$ sebesar 5.19. Karena $F_{\text {hitung }}<F_{\text {tabel }}(0.176<5.19)$. Sedangkan nilai Sig $>\alpha(0.697>0.05)$ maka dapat disimpulkan bahwa tidak terdapat kontribusi yang signifikan dari latihan back-up terhadap servis slice. Hasil analisis statistik latihan hand grip dan latihan back-up terhadap servis slice diperoleh $\mathrm{F}=0.069$ dan nilai Sig. 0.935. Uji keberartian persamaan regresi dapat dilakukan dengan uji F dan juga Sig. Sehingga dari hasil perhitungan diperoleh $F_{\text {hitung }} 0.069$ dan $F_{\text {tabel }(3,5)}$ sebesar 5.41. Karena $F_{\text {hitung }}<F_{\text {tabel }}$ $(0.176<5.41)$. Sedangkan nilai Sig $>\alpha(0.935>0.05)$ maka dapat disimpulkan bahwa tidak terdapat kontribusi yang signifikan dari latihan hand grip dan latihan back-up terhadap servis slice.
\end{abstract}

Kata Kunci: Hand grip, Back-up, Servis slice

\section{Contribution of Hand Grip and Back-Up Exercise on Slice Services in The Unimed Tennis Community's Athletes}

\begin{abstract}
This study aims to determine the contribution of hand grip and back up exercise to slice service in tennis. The sample of this study was 6 male athletes obtained by purposive sampling technique. The instruments used in this study were the grip strength dynamometer for grip strength, trunk and neck flexibility test for flexibility, and the serve test for slice service. The results of the statistical analysis of hand grip exercises for slice service obtained Fcount 0.151 and Ftable (4.5) of 5.19. Because Fcount <Ftable (0.151 <5.9). While the value of Sig> $\alpha(0.717>0.05)$, it can be concluded that there is no significant contribution from hand grip training to slice service. The results of statistical analysis of back-up training on slice service obtained Fcount 0.176 and Ftable (4.5) of 5.19. Because Fcount <Ftable $(0.176<5.19)$. While the value of Sig > $\alpha(0.697>0.05)$, it can be concluded that there is no significant contribution from back-up training to slice service. The results of statistical analysis of hand grip exercises and back-up exercises for slice service obtained $F=0.069$ and the value of Sig. 0.935. The regression equation meaningful test can be done with the F test and also the Sig. So that the calculation results obtained Fcount 0.069 and Ftable (3.5) of 5.41. Because Fcount <Ftable $(0.176<5.41)$. While the value of Sig> $\alpha(0.935>0.05)$, it can be concluded that there is no significant contribution from hand grip training and back-up training to slice service.
\end{abstract}

Keywords: Hand grip, Back-up, Slice service 


\section{PENDAHULUAN}

Tenis lapangan merupakan salah satu jenis olahraga yang popular dan banyak digemari semua lapisan masyarakat di dunia khususnya di Indonesia. Tenis lapangan adalah olahraga yang biasanya dimainkan antara dua pemain atau antara dua pasangan dengan masing-masing dua pemain. Setiap pemain menggunakan raket untuk memukul bola. Tujuan permainan adalah memainkan bola dengan cara tertentu sehingga pemain lawan tidak dapat mengembalikan bola tersebut. Tenis lapangan sampai saat ini telah berkembang pesat dan sudah dipertandingkan sebagai olahraga prestasi. Olahraga prestasi mempunyai ciri iklim kompetitif yang tinggi sehingga mendorong para atlet untuk terus berlatih dan meningkatkan kemampuannya.

Di dalam permainan tenis lapangan, terdapat beberapa teknik dasar yang harus dikuasai yaitu: (a) service (servis), (b) forehand drive (groundstroke), (c) backhand drive (groundstroke), dan (d) volley (Scharff R, 2001:24). Servis dalam perkembangan tidak lagi dianggap sebagai permulaan permainan, tetapi merupakan bentuk serangan pertama. Maka demikian servis harus dilakukan sebaik mungkin agar lawan sulit mengembalikan bola, sehingga menghasilkan poin bagi pemain yang melakukan servis. Agar mendapatkan hasil latihan yang efektif dan efisien perlu disertai dengan bimbingan dan evaluasi terhadap kemampuan servis para atlet tenis lapangan.

Komunitas tenis lapangan Unimed adalah salah satu komunitas tennis Medan yang menampung minat dan bakat mahasiswa dalam bermain tenis lapangan. Adapun anggota dari komunitas ini adalah mahasiswa FIK Unimed yang mengikuti latihan pada sore hari. Peneliti telah melakukan beberapa kali pengamatan dan observasi di komunitas ini pada saat melakukan latihan rutin. Berdasarkan observasi yang dilakukan penulis pada komunitas tenis lapangan Unimed bahwa saat ini, baik dalam latihan maupun dalam turnamen yang beberapa kali dilaksanakan, masih banyak pemain yang belum mampu melakukan servis dengan baik. Hal ini terlihat dari pergerakannya saat akan melakukan pukulan servis masih banyak servis yang keluar, menyangkut di net dan tidak tepat sasaran. Dari tiga (3) jenis servis yang terdapat dalam permainan tenis lapangan yaitu, Slice, Twist, dan flat, kebanyakan dari pemain tersebut menggunakan jenis servis flat dan slice. Hal tersebut dapat dilihat pada saat pemain melakukan latihan sore serta melakukan pertandingan antar anggota komunitas.

Hasil observasi penulis ditemukan bahwa servis slice yang dilakukan oleh pemain cenderung mendapatkan poin karena pukulan servis slice menghasilkan putaran bola yang sulit dikembalikan oleh lawan. Hal tersebut membuat penulis tertarik pada teknik servis slice. Setelah melakukan observasi, penulis melakukan tes dan pengukuran terhadap kemampuan servis slice pada komunitas tenis Unimed.

Kekuatan dan kelentukan adalah dua elemen kondisi fisik yang mempengaruhi keterampilanketerampilan gerakan pada saat melakukan teknik servis slice. Didalam hal ini kekuatan genggaman merupakan salah satu bagian yang sangat penting pada saat melakukan servis slice. Jika genggaman anda lemah, maka lawan anda akan memiliki kesempatan yang lebih besar untuk mendapatkan angka dalam setiap serangan. Sebaliknya jika pukulan yang dilakukan dengan genggaman yang kuat maka kesempatan anda untuk mendapatkan ace menjadi lebih besar.

Selanjutnya dalam melakukan teknik servis slice kelentukan dibutuhkan untuk mendorong hasil servis yang lebih optimal. Kelentukan merupakan efektivitas seseorang dalam menyesuaikan diri untuk segala aktivitas dengan penguluran tubuh pada bidang sendi yang luas. Oleh karena itu kelentukan sangat dibutuhkan oleh seseorang pemain tenis lapangan. Jika kelentukan kurang bisa mengakibatkan kurangnya hentakan/dorongan, cidera dan tidak leluasa atau gesit pada saat melakukan servis. Kelentukan yang dapat memberikan dorongan lebih pada saat melakukan servis slice adalah kelentukan pinggang. Hal ini dapat dilihat dari pelaksanaannya ketika pinggang dilentingkan kebelakang dan dibawa ke posisi menghadap net untuk mengarahkan servis. Jadi seorang atlet yang memiliki kekuatan genggaman dan kelentukan pinggang yang baik, akan mampu menghasilkan pukulan servis yang tepat dan mampu menempatkan bola kedaerah yang jauh dari jangkauan lawan.

Kemudian untuk mendapatkan kekuatan genggaman dan kelentukan pinggang yang baik maka diperlukan latihan yang dapat meningkatkan kedua komponen tersebut. Salah satu cara untuk melatih kekuatan genggaman tangan atlet tenis lapangan adalah menggunakan latihan hand grip. Hal itu dapat dilakukan menggunakan resistance band, dumbbell, atau lainnya, Sedangkan untuk melatih kelentukan pinggang dapat dilakukan dengan metode latihan back-up. 
Dari uraian diatas jelas bahwa pukulan servis slice sangat berkaitan dengan komponen kondisi fisik terutama kekuatan genggaman dan kelentukan pinggang. Kurangnya kemampuan atlet dalam melakukan pukulan servis slice juga diduga karena kurangnya kondisi fisik pemain khususnya kekuatan genggaman dan kelentukan pinggang. Berdasarkan pemasalahan diatas maka penulis tertarik untuk mengetahui lebih jauh kemampuan atlet dalam melakukan pukulan servis slice.

Pada permainan tenis, persendian yang paling penting adalah kaki, pinggang, bahu, siku dan pergelangan tangan. Gerakan dimulai dengan bekerjanya grup-grup otot besar dan terus bergerak secara progresif melalui otot-otot kecil. Gerakan mengalir terus menerus ini menghasilkan suatu pengumpulan kekuatan yang disatukan. Kekuatan ini digerakkan oleh satu bagian tubuh yang terbentuk dari kekuatan sendi-sendi berikutnya.

Gerakan persendian pada saat melakukan servis slice dimulai dari analisa persendian kaki atau kedua tungkai sebagai kaki tumpu pada gerakan awalan, fleksi lutut (kontraksi eksentrik dari paha depan) terjadi untuk memicu gaya dorong permukaan tanah secara efektif, dimana hal tersebut menjadi aspek penghasil gaya utama dari gerakan servis, fleksi lutut ini sering diartikan sebagai beban tubuh bagian bawah. Gastrocnemius, soleus, quardiceps, gluteal, dan rotator pinggul berkontraksi secara eksentrik untuk memuat tungkai dan memulai rotasi pinggul. Kemudian posisikan lengan, badan dan pergelangan tangan ketika memegang bola dan raket. Manakala gerakan melempar bola, mengayun raket posisi badan menghadap kearah jaring/net persendian bahu dan sikut sangat dominan berperan. Ketika lepasnya bola dari tangan dan ayunan raket ke belakang persendian pangkal tangan (pergelangan tangan) sangat dominan berperan. Selama tahap mengangkat lengan saat melakukan servis titik rotasi bahu eksternal maksimal, bahu dominan dapat diputar hingga 170 derajat. ekstensor punggung, obliques, dan perut berkontraksi secara konsentris dan aksen untuk memperpanjang dan memutar batang. kontraksi konsentris dari infraspinatus, teres minor, supraspinatus, bisep, serratus anterior, dan ekstensor pergelangan tangan dan kontraksi aksen dari subskapularis dan pektoralis mayor menggerakkan lengan. Dari posisi ini terdapat komponen vertikal yang mengakibatkan kontraksi konsentris dari otot-otot utama lengan dan bahu yang dominan.

Otot-otot dibagian depan dada dan batang tubuh (otot-otot qudriceps, dan bisep) adalah otot pemacu utama pada lengan atas, sedangkan otot-otot dibagian belakang tubuh (otot manset rotator, trapezius, rhomid, dan ekstensi belakang) adalah perlambatan utama selama pelaksanaan servis. Pada saat siku terbuka otot trisep dan bisep berkontraksi. Pada saat memutar bahu, otot yang berkontraksi yaitu lattisimus dorsi, subscapularis, pectoralis. Sedangkan pada saat menekuk pergelangan tangan dibuat melalui kontraksi konsentris dari fleksi pergelangan tangan.

Servis dalam permainan tenis lapangan ada beberapa macam servis yang bisa digunakan sesuai pendapat Scharff R (2001:60) "Ada tiga macam jenis servis yaitu: slice, twist, dan flat". Servis Slice merupakan teknik servis dengan cara memotong atau mengesek untuk mendapatkan putaran bola. Ketika servis slice ini, raket menyentuh bola pada bagian kanan sebelah atas dan bola dipukul dengan putaran raket dari kanan ke kiri bagi pemain yang tidak kidal, bagi yang kidal sebaliknya. Hal ini sesuai dengan pendapat Yudoprasetio (2002:106) yang menyatakan "raket harus dilecutkan ke depan dengan hentakan keras dari pergelangan tangan". Akibat dari cara slice atau memotong atau menggesek ini menyebabkan bola berputar ke samping. Hal ini menguntungan bagi pemain yang melakukan servis yaitu bola yang berputar kencang ke samping kanan setelah jatuh dalam kotak servis lawan, memantul dan cepat membelok ke samping kanan penerima.

Mageti (1999:15-16) servis slice adalah bola yang ditoss kurang lebih $10 \mathrm{~cm}$ di muka dan $30 \mathrm{~cm}$ di sebelah kanan kepala, dipukul pada belakang kanan, digesek dari kiri ke kanan. Slice merupakan pukulan memotong (mengiris) untuk memberikan efek pada bola yang ditoss. Lardner, (2013:41) servis slice memungkinkan pelaku servis memukul bola cukup keras yang tetap dikendalikan dengan spin menyamping (sidespin).

Proses latihan merupakan sebuah proses yang tidak terhindarkan untuk menganut hukum tertentu secara empirik dan keilmuan yang telah terbukti dan teruji secara jelas seiring dengan perkembangan ilmu pengetahuan. Oleh karena itu hasil latihan tidak selalu positif dan optimal bila pembebanan tidak dilakukan dengan kaidah hukum dan prinsip latihan yang benar (Lumintuarso dalam Hadi, 2007:53) Tujuan latihan adalah untuk membantu seorang atlet atau satu tim olahraga dalam meningkatkan 
ketrampilan atau prestasinya semaksimal mungkin dengan mempertimbangkan berbagai aspek latihan yang harus diperhatikan, meliputi latihan fisik, teknik, taktik dan latihan mental.

Akhmad (2013:4) mengatakan bahwa "Tugas utama latihan adalah menggali, menyusun, dan mengembangkan konsep berlatih dengan memadukan antara pengalaman praktis dan pendekatan keilmuan, sehingga proses melatih dapat berlangsung tepat, cepat, efektif, dan efisien. Berdasarkan pendapat dari beberapa ahli di atas, maka dapat disimpulkan bahwa pengertian latihan adalah aktifitas yang meningkatkan keterampilan (kemahiran) yang dilakukan secara sistematis, berlatih dan berulangulang. Efek-efek latihan sangat berpengaruh pada pengembangan individual atlet baik fisik, tehnik maupun taktik. Latihan adalah upaya atlet untuk meningkatkan kemampuannya yang dilakukan secara teratur, terarah dan dilakukan secara berulang - ulang. Latihan sangat mempengaruhi performa atlet baik itu fisik maupun teknik dan taktik. Maka proses latihan harus diperhatikan dengan baik agar tujuan latihan dapat tercapai.

Hand Grip adalah jenis latihan yang bertujuan meningkatkan kemampuan otot atau sekelompok otot untuk melakukan satu kali kontraksi secara maksimal melawan tahanan atau beban. Secara mekanis kekuatan otot di definisikan sebagai gaya (force) yang dapat dihasilkan otot atau sekelompok otot dalam suatu kontraksi maksimal Widiastuti (2017: 75). Latihan pegangan tangan dapat dilakukan dengan beberapa bentuk latihan diantaranya latihan menggunakan resistance band dan dumbbell. Menurut Romadhon (2017 : 50) Resistance band merupakan alat olahraga fitnes yang efisien dan mudah dibawabawa terbuat dari karet. Resistance band terdapat handle (pegangan) untuk memudahkan pengguna dalam menggunakan latihan resistance band.

Latihan resistance band memperkuat otot tubuh manusia, memperkuat stabilitas sekelompok otot. Didalam cabang olahraga tenis lapangan, latihan ini dapat digunakan untuk melatih kekuatan. Hal kekuatan yang dimaksud adalah kekuatan genggaman pada saat melakukan servis slice tenis lapangan. Bentuk latihan resistance band terdapat beberapa variasi latihan yang akan digunakan dalam penelitian ini yaitu: 1) two-arm lateral raise, 2) bicep curls, 3) arm triceps extensions.

Dumbbell adalah seperangkat peralatan latihan beban yang terdiri dari sepotong bar pendek dengan lempengan beban pada setiap sisinya dan digunakan dalam latihan-latihan menggunakan satu lengan tangan (Baechle, Thomas R, 2003:XII). Dumbbell yang digunakan untuk melatih pergelangan tangan dengan bert $1 \mathrm{~kg}$. Jenis latihan dumbbell yang digunakan yaitu dumbbell wrist. Dumbbell wrist adalah latihan pergelangan tangan dengan cara melakukan flexy dan ekstensi. Semakin lentuk pergelangan tangan maka akan mempermudah pemain melakukan pukulan, sehingga pukulan yang dihasilkan semakin baik pula.

Adapun bentuk latihan yang juga digunakan dalam penelitian ini yakni latihan back-up yang ditujukan untuk melatih kelentukan. Harsono mengatakan "adapun latihan untuk mengembangkan kelentukan adalah sebagai berikut: berbaring telungkup, kemudian mengangkat kepala dan dada berkalikali setinggi-tingginya keatas". Perbaikan dalam kelentukan diharapkan membantu dalam pengembangan kecepatan, koordinasi, dan kelincahan seorang atlet tenis.

\section{METODE}

Metode yang digunakan dalam penelitian ini adalah metode eksperimen dengan teknik pengambilan data yang melibatkan dua variabel bebas yaitu Hand grip $\left(\mathrm{X}_{1}\right)$ dan Back-up $\left(\mathrm{X}_{2}\right)$ terhadap variabel terikat yaitu kemampuan servis slice $(\mathrm{Y})$ dalam permainan tenis lapangan. Adapun sampel penelitian ini berjumlah 6 orang diperoleh dengan teknik purposive sampling. Instrumen yang digunakan dalam penelitian ini adalah grip strength dynamometer untuk kekuatan genggaman, trunk and neck flexibility test untuk kelentukan, serve test untuk servis slice.

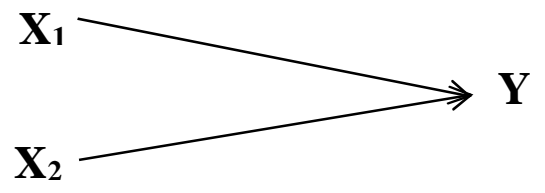

Gambar 1. Desain Penelitian 


\section{HASIL DAN PEMBAHASAN}

Perhitungan kontribusi dari antara variavel hand grip $\left(\mathrm{X}_{1}\right)$ terhadap servis slice tenis lapangan $(\mathrm{Y})$ terlebih dahulu mencari persamaan regresi. Persamaan regresi tersebut dianalisis dari hasil output SPSS pada tabel coeficient yang ditunjukkan pada kolom B yaitu baris constant yaitu sebesar 36.21 sedangkan pada baris hand grip adalah (-0.349). Dari hasil tersebut ditulis persamaan regresi berikut $\mathrm{Y}=36.21+$ (-0.349) $\mathrm{X}_{1}$. Untuk mengetahui besarnya hubungan atau korelasi antara hand grip $\left(\mathrm{X}_{1}\right)$ terhadap kemampuan servis slice tenis lapangan $(\mathrm{Y})$ menggunakan tabel model summary yang mana besarnya nilai korelasi/hubungan (R) yaitu sebesar 0.191 Dari hasil tersebut dapat disimpulkan bahwa hubungan antara hand grip terhadap kemampuan servis slice tenis lapangan adalah rendah.

Untuk melihat besaran hubungan tersebut dari nilai $\mathrm{R}^{2}$ yaitu sebesar 0.036 sehingga besarnya determinasi hand grip terhadap kemampuan servis slice tenis lapangan adalah sebesar $3.6 \%$ sedangkan 96.4\% dipengaruhi oleh variabel lain. Untuk mengetahui besaran korelasi atau hubungan tersebut signifikan atau tidak, maka dilakukan uji keberartian dengan uji t menggunakan tabel coeficient. Dari tabel tersebut diketahui bahwa $t_{\text {hitung }}=0.829$. Untuk mengetahui besaran $t_{\text {tabel }}$ dengan taraf $\alpha+0,05$ dan $\mathrm{dk}=\mathrm{n}-1=5$, melalui daftar distribusi $t$ dengan menggunakan peluang $1-\alpha=0.95$ sehingga diperoleh harga $t_{\text {tabel }}(4,095)=2.015$. Didalam kriteria pengujian hipotesis satu arah dinyatakan bahwa $t_{\text {hitung }}<t_{\text {tabel }}$ yaitu $(0.83<2.015)$. Maka disimpulkan bahwa korelasi atau hubungan sebesar $3.6 \%$ dari latihan hand grip terhadap kemampuan servis slice tenis lapangan tidak signifikan. Setelah mendapatkan persamaan $\mathrm{Y}=36.21+(-0.349) \mathrm{X}_{1}$, maka dilanjutkan dengan menguji persamaan tersebut apakah berarti atau tidak.

Untuk melakukan persamaan regresi digunakan tabel anova yang mana pada tabel output spss hasil analisis regresi diperoleh nilai $\mathrm{F}=0.151$ dan nilai Sig. 0.717. Uji keberartian persamaan regresi dapat dilakukan dengan uji $F$ dan juga Sig. Sehingga dari hasil perhitungan diperoleh $F_{\text {hitung }} 0.151$ dan $F_{\text {tabel }}(4,5)$ sebesar 5.19. Karena $F_{\text {hitung }}<F_{\text {tabel }}(0.151<5.9)$. Sedangkan nilai Sig $>\alpha(0.717>0.05)$ maka dapat disimpulkan bahwa tidak terdapat kontribusi yang signifikan dari latihan hand grip terhadap servis slice.

Perhitungan kontribusi dari antara variabel back-up $\left(\mathrm{X}_{2}\right)$ terhadap servis slice tenis lapangan terlebih dahulu mencari persamaan regresi. Persamaan regresi tersebut dianalisis dari hasil output SPSS pada tabel coeficient yang ditunjukkan pada kolom B yaitu baris constant yaitu sebesar $(-2.480)$ sedangkan pada baris hand grip adalah 0.391 Dari hasil tersebut ditulis persamaan regresi berikut $\mathrm{Y}=$ $(-2.480)+0.391 \mathrm{X}_{1}$. Untuk mengetahui besarnya hubungan atau korelasi antara back-up $\left(\mathrm{X}_{2}\right)$ terhadap servis slice tenis lapangan (Y) menggunakan tabel model summary yang mana besarnya nilai korelasi/hubungan (R) yaitu sebesar 0.205. Dengan demikian dapat disimpulkan bahwa hubungan antara back-up terhadap kemampuan servis slice tenis lapangan adalah rendah.

Untuk melihat besaran hubungan tersebut dari nilai $\mathrm{R}^{2}$ yaitu sebesar 0.042 sehingga besarnya determinasi backup terhadap kemampuan servis slice tenis lapangan adalah sebesar $4.2 \%$ sedangkan 95.8\% dipengaruhi oleh variabel lain. Untuk mengetahui besaran korelasi atau hubungan tersebut signifikan atau tidak, maka dilakukan uji keberartian dengan uji t menggunakan tabel coeficient. Dari tabel tersebut diketahui bahwa $t_{\text {hitung }}=-0.047$. Untuk mengetahui besaran $t_{\text {tabel }}$ dengan taraf $\alpha+0.05$ dan $\mathrm{dk}=\mathrm{n}-1=5$, melalui daftar distribusi $t$ dengan menggunakan peluang $1-\alpha=0.95$ sehingga diperoleh harga $\mathrm{t}_{\text {tabel }(4,095)}=2.015$. Dalam kriteria pengujian hipotesis satu arah dinyatakan bahwa $\mathrm{t}_{\text {hitung }}<\mathrm{t}_{\text {tabel }}$ yaitu (-0.047 <2.015). Maka disimpulkan bahwa korelasi atau hubungan sebesar $4.2 \%$ dari latihan back-up terhadap kemampuan servis slice tenis lapangan tidak signifikan.

Setelah mendapatkan persamaan $\mathrm{Y}=(-2.480)+0.391 \mathrm{X}_{1}$, maka dilanjutkan dengan menguji persamaan tersebut apakah berarti atau tidak. Untuk melakukan persamaan regresi digunakan tabel anova yang mana pada tabel output spss hasil analisis regresi diperoleh nilai $\mathrm{F}=0.176$ dan nilai Sig. 0.697. Uji keberartian persamaan regresi dapat dilakukan dengan uji F dan juga Sig. Sehingga dari hasil perhitungan diperoleh $F_{\text {hitung }} 0.176$ dan $F_{\text {tabel }}(4,5)$ sebesar 5.19. Karena $F_{\text {hitung }}<F_{\text {tabel }}(0.176<5.19)$. Sedangkan nilai Sig $>\alpha(0.697>0.05)$ maka dapat disimpulkan bahwa tidak terdapat kontribusi yang signifikan dari latihan back-up terhadap servis slice.

Penghitungan besar kontribusi antar variabel yang terlebih dahulu di uji adalah persamaan regresi. Persamaan regresi antara hand grip $\left(\mathrm{X}_{1}\right)$ dan back-up $\left(\mathrm{X}_{2}\right)$ terhadap servis slice tenis lapangan $(\mathrm{Y})$ dianalisis dari hasil output SPSS pada tabel coeficient yang ditunjukkan pada kolom B yaitu baris constant yaitu sebesar 10.482 sedangkan pada baris hand grip adalah (-0.177) dan pada kolom back-up 
adalah 0.277. Dari hasil tersebut ditulis persamaan regresinya sebagai berikut. $\mathrm{Y}=10.482+(0.177) \mathrm{X}_{1}$ $+0.277 \mathrm{X}_{2}$. Untuk mengetahui besarnya hubungan atau korelasi antara hand grip $\left(\mathrm{X}_{2}\right)$ dan back-up $\left(\mathrm{X}_{2}\right)$ terhadap servis slice tenis lapangan (Y) menggunakan tabel model summary yang mana besarnya nilai korelasi/hubungan $(\mathrm{R})$ yaitu sebesar 0.210 dengan demikian dapat disimpulkan bahwa hubungan antara hand grip dan back-up terhadap kemampuan servis slice tenis lapangan adalah rendah. Untuk melihat besaran hubungan tersebut dari nilai $\mathrm{R}^{2}$ yaitu sebesar 0.044 sehingga besarnya determinasi hand grip terhadap kemampuan servis slice tenis lapangan adalah sebesar 4.4\% sedangkan 95.6\% dipengaruhi oleh variabel lain.

Untuk mengetahui besaran korelasi atau hubungan tersebut signifikan atau tidak, maka dilakukan uji keberartian dengan uji t menggunakan tabel coeficient. Dari tabel tersebut diketahui bahwa $t_{\text {hitung }}=$ 0.061. Untuk mengetahui besaran $\mathrm{t}_{\text {tabel }}$ dengan taraf $\alpha+0.05 \mathrm{dan} \mathrm{dk}=\mathrm{n}-1=5$, melalui daftar distribusi $t$ dengan menggunakan peluang $1-\alpha=0.95$ sehingga diperoleh harga $t_{\text {tabel }}(4,095)=2.015$. Dalam kriteria pengujian hipotesis satu arah dinyatakan bahwa $t_{\text {hitung }}<t_{\text {tabel }}$ yaitu $(0.061<2.015)$. Maka disimpulkan bahwa korelasi atau hubungan sebesar $4.4 \%$ dari latihan back-up terhadap kemampuan servis slice tenis lapangan tidak signifikan.

Setelah mendapatkan persamaan. $\mathrm{Y}=10.482+(0.177) \mathrm{X}_{1}+0.277 \mathrm{X}_{2}$, maka dilanjutkan dengan menguji persamaan tersebut apakah berarti atau tidak. Untuk melakukan persamaan regresi digunakan tabel anova yang mana pada tabel output spss hasil analisis regresi diperoleh nilai $\mathrm{F}=0.069$ dan nilai Sig. 0.935. Uji keberartian persamaan regresi dapat dilakukan dengan uji F dan juga Sig. Sehingga dari hasil perhitungan diperoleh $\mathrm{F}_{\text {hitung }} 0,069$ dan $\mathrm{F}_{\text {tabel }(3,5)}$ sebesar 5.41. Karena $\mathrm{F}_{\text {hitung }}<\mathrm{F}_{\text {tabel }}(0.176<5.41)$. Sedangkan nilai Sig $>\alpha(0.935>0.05)$ maka dapat disimpulkan bahwa tidak terdapat kontribusi yang signifikan dari latihan hand grip dan latihan back-up terhadap servis slice.

\section{SIMPULAN}

Dari hasil pengujian hipotesis dengan analisis statistik regresi ditarik kesimpulan bahwa: (1) tidak terdapat kontribusi yang signifikan dari latihan hand grip terhadap servis slice pada atlet putra komunitas tenis lapangan Unimed, (2) tidak terdapat kontribusi yang signifikan dari latihan back-up terhadap servis slice pada atlet putra komunitas tenis lapangan Unimed, (3) tidak terdapat kontribusi yang signifikan dari latihan hand grip dan latihan back-up terhadap servis slice pada atlet putra komunitas tenis lapangan Unimed.

\section{DAFTAR PUSTAKA}

Harsono. (2009). Latihan Kondisi Fisik. Jakarta: PT Rineka Cipta.

Magheti, Bey. (2000). Tenis Para Bintang. Bandung: CV Pioner Jaya

Roetert, Paul dan Kovacs Mark. (2011). Tennis Anatomy.United State. Human Kinetic.

Romadhon. (2017).Pengaruh latihan menggunakan resistance band terhadap power tungkai atlet UKM taekwondo UNY.Skripsi sarjana,tidak diterbitkan. Universitas Negeri Yogyakarta,Yogyakarta

Hadi, Rubianto. (2007). Ilmu Kepelatihan Dasar. Semarang. CV Cipta Prima Nusantara.

Scharff, R. (2001). Bimbingan Main Tennis Cepat Dan Mudah. Jakarta: Mutiara

Widiastuti. (2017). Tes Dan Pengukuran Olahraga. Jakarta: PT RajaGrafindo Persada

Yudoprasetio, (2002). Belajar Tenis I “The Thre Stroke Game”. Jakarta: Bhara Karya Aksara. 